\title{
An evaluation of Brix refractometry instruments for measurement of colostrum quality in dairy cattle
}

\author{
V. Bielmann, ${ }^{* 1}$ J. Gillan, ${ }^{*}$ N. R. Perkins, ${ }^{*}$ A. L. Skidmore,† S. Godden, $\ddagger$ and K. E. Leslie \\ *Department of Population Medicine, University of Guelph, Guelph, Ontario, Canada N1G 2W1 \\ †Schering-Plough Animal Health, Alexander, NY 14005 \\ ‡Department of Veterinary Population Medicine, University of Minnesota, St. Paul 55108
}

\section{ABSTRACT}

Acquisition of high quality colostrum is an important factor influencing neonatal calf health. Many methods have been used to assess the Ig concentration of colostrum; however, improved, validated evaluation tools are needed. The aims of this study were to evaluate both optical and digital Brix refractometer instruments for the measurement of $\mathrm{Ig}$ concentration of colostrum as compared with the gold standard radial immunodiffusion assay laboratory assessment and to determine the correlation between Ig measurements taken from fresh and frozen colostrum samples for both Brix refractometer instruments. This research was completed using 288 colostrum samples from 3 different farms. It was concluded that the optical and digital Brix refractometers were highly correlated for both fresh and frozen samples ( $r=0.98$ and $r=0.97$, respectively). Correlation between both refractometer instruments for fresh and frozen samples and the gold standard radial immunodiffusion assay were determined to be very similar, with a correlation coefficient between 0.71 and 0.74. Both instruments exhibited excellent test characteristics, indicating an appropriate cut-off point of $22 \%$ Brix score for the identification of good quality colostrum.

Key words: colostrum quality, Brix refractometer, failure of passive transfer, immunoglobulin

\section{INTRODUCTION}

Colostrum, the initial secretion from the mammary gland after parturition, is an important source of immunity and nutrition for the neonate. It contains functional proteins, Ig, fat, minerals, and vitamins to ensure future health. The most important factor influencing calf health and future production is ensuring adequate intake of high quality colostrum as soon as possible after

Received November 24, 2009.

Accepted April 3, 2010.

${ }^{1}$ Corresponding author: vbielman@uoguelph.ca birth. The failure of passive transfer (FPT) of Ig results in an increased morbidity and mortality of calves as a result of an increased susceptibility to pathogens and subsequent disease (McEwan et al., 1970; Boyd, 1972; McGuire et al., 1976). The definition of FPT is a low concentration of $\operatorname{IgG}$ in the serum between 24 and $48 \mathrm{~h}$ of age. Radial immunodiffusion assays (RID) are the gold standard for determining serum IgG concentration. Measurement of total proteins (TP) in the blood is an indirect measure of IgG concentration and can be determined by refractometry. A calf is considered to be suffering from FPT if serum IgG concentration is less than $10 \mathrm{mg} / \mathrm{mL}$ (Weaver et al., 2000) or serum protein levels are less than 5.2 to $5.5 \mathrm{~g} / \mathrm{dL}$ (Naylor and Kronfeld, 1977). The National Dairy Heifer Evaluation Project conducted in 1993 by the National Animal Health Monitoring System (Fort Collins, CO) reported that more than $40 \%$ of calves tested for serum Ig levels 24 to $48 \mathrm{~h}$ postpartum had levels below $5.0 \mathrm{~g} / \mathrm{dL}$. Additionally, other studies have indicated that FPT is highly prevalent, with $35 \%$ of calves affected in the United States (Tyler et al., 1998). An extensive investigation was completed to determine the prevalence of FPT on dairy farms throughout southern Ontario (TrotzWilliams et al., 2008). This herd-level study measured TP concentrations of 422 calves, 1 to $7 \mathrm{~d}$ of age, among 112 farms. In this study, $37.1 \%$ of calves showed FPT, defined as a serum TP concentration below $5.2 \mathrm{~g} / \mathrm{dL}$. Most recently, Beam et al. (2009) reported the prevalence of FPT in heifer calves in the United States to be $19.2 \%$. However, $40.7 \%$ of US operations had at least 1 calf with FPT. Thus, although the overall levels of FPT are decreasing, it is still a considerable issue on many dairy farms. Clearly, there is a widespread need for improved calf and colostral management practices to ensure optimal calf health. One key component to achieve this goal could be the implementation of useful tools for the assessment of colostrum quality.

Colostrum varies among animals depending on parity, breed, season, time until first milking, and prepartum diet (Donovan et al., 1986; Moore et al., 2005; Gulliksen et al., 2008). A variety of methods are available 
to evaluate colostrum quality. However, not all of these techniques are conducive to on-farm use. An effective on-farm tool should be inexpensive, rapid, easy to use, and accurate. The most accurate method of evaluating the colostral Ig content is RID (Oyeniyi and Hunter, 1978; Fleenor and Stott, 1980). This method is considered to be the gold standard for comparison with other methods. Unfortunately, the RID is a laboratory assessment that requires approximately 18 to $24 \mathrm{~h}$ to determine the results. As such, it is not conducive to on-farm application. A hydrometer measures the specific gravity of a liquid. In the case of colostrum, the specific gravity is highly correlated to TS. Protein accounts for a high proportion of TS, and globulins represent a large portion of this protein. Thus, the specific gravity of colostrum is correlated to its Ig content (Fleenor and Stott, 1980). Pritchett et al. (1994) later compared the hydrometer with the RID to determine an appropriate cut-off point indicative of high or low levels of Ig in a colostrum sample. For a 2.84-L feeding of colostrum, a cut-off of $50 \mathrm{mg} / \mathrm{mL}$ had a low sensitivity of $32 \%$ and specificity of $97 \%$. The researchers determined that misclassification of colostrum was minimized when the cut-off point was increased to between 60 and $85 \mathrm{mg} / \mathrm{mL}$. The 2007 National Animal Health Monitoring System dairy study determined that approximately $13 \%$ of US dairy operations that hand-fed colostrum evaluated the quality of colostrum before feeding it to calves. The colostrometer was the most common method of evaluating colostrum (43.7\%), followed closely by visual assessment (41.6\%). Colostrometers are well suited to on-farm use because it only takes minutes to use, yet they are temperature sensitive (Mechor et al., 1992) and fragile. Recently, a Brix refractometer was reported to be a useful method for the evaluation of the TS content of waste milk for nutritional management on calf ranches (Moore et al., 2009). Unlike the colostrometer, the Brix refractometer is not sensitive to the temperature of the colostrum at the time of analysis. A recent study by Bielmann et al. (2008) analyzed a subset of the colostrum samples at 3 different temperatures: 5,20 , and $38^{\circ} \mathrm{C}$. No significant differences were found between the Brix scores taken at the 3 different sample temperatures. Furthermore, the Brix instrument was evaluated for measurement of colostrum Ig concentration in mares (Chavatte et al., 1998). These reports provide optimism for the usefulness of the Brix instrument as a tool for on-farm monitoring of colostrum quality. The objectives of this study were to evaluate both optical and digital Brix refractometer instruments for the measurement of Ig concentration of colostrum compared with the gold standard RID laboratory assessment and to determine the correlation between measurements taken from fresh and frozen colostrum samples.

\section{MATERIALS AND METHODS}

\section{Colostrum Sample Source and Collection}

An evaluation of the optical (Animal Reproduction Systems, Chino, CA) and digital (Atago Co. Ltd., Bellevue, WA) Brix refractometer instruments was performed using colostrum from 288 Holstein dairy cows from the University of Guelph Elora Dairy Research Centre (Elora, Ontario, Canada), a commercial herd in eastern Ontario, Canada, and from the University of Minnesota Transition Management Facility (Emerald Dairy II, Emerald, WI). Two samples of colostrum were collected from the first milking for analysis. The number of samples analyzed was based on a convenience sampling in 3 herds. Samples were collected from fresh cows from March 2008 to January 2009. Both the digital and optical Brix refractometers measure the refractometric index of liquids on a Brix scale. The optical Brix refractometer requires an individual to peer into the instrument and determine the percentage Brix of the liquid being analyzed by identifying a blue line on the scale. The digital Brix determines the Brix score of the liquid by shining a light through the sample in the well, measuring the index of refraction, and presenting the reading in Brix units on a digital scale. The optical Brix refractometer values may be interpreted differently by different people, whereas the digital Brix refractometer may provide more consistent results if used and cleaned properly. However, functionally, both the optical and digital Brix refractometers measure and operate in the same manner, measuring the refractive index of a liquid.

\section{Colostrum Sample Analysis}

Of the 2 samples taken, one sample was measured within $1 \mathrm{~h}$ of collection with both optical and digital Brix refractometers and was considered to be the fresh sample. If the readings could not be taken within that time frame, the sample was refrigerated until measurements could be taken. The other sample was frozen for $2 \mathrm{~d}$ at $-20^{\circ} \mathrm{C}$ and then thawed to room temperature. Colostrum samples that were refrigerated or frozen and then thawed were inverted 10 to 12 times to thoroughly mix the colostrum for an accurate measure of the quality of the sample. Then, the sample was measured with the optical and digital Brix instruments. This was considered to be the frozen sample. As such, each animal's colostrum had 4 Brix score (\%) results, 1 measurement for each instrument at both fresh and frozen-thawed states. The optical refractometer had an upper limit on the scale of $32.0 \%$. Therefore, those samples that had a reading that surpassed $32.0 \%$ were assigned a measurement of $32.0 \%$. After measurements were taken from the 
fresh sample, it was then frozen and stored at $-20^{\circ} \mathrm{C}$ until it could be shipped to the Saskatoon Colostrum Company (Saskatoon, Saskatchewan, Canada) for analysis of serum IgG concentration by RID as described by Chelack et al. (1993). To ensure little plate-to-plate variation, quality control measures are implemented for each plate. A standard curve is made with Midlands bovine serum calibrator (1/4-1/32; Midland Bioproducts Corporation, Boone, IA) to obtain Ig concentrations of approximately $8.7,4.35,2.18$, and $1.09 \mathrm{~g} / \mathrm{L}$. This is dispensed twice per plate. For each plate, 5 replicates of USDA bovine serum reference (Midland Bioproducts Corp.) at $1 / 4$ of working stock, as well as 5 replicates of the Saskatoon Colostrum Company's own colostrum standard diluted at $1 / 30$ (this standard has been approved by the Canadian Food Inspection Agency) are used All plates are incubated for $18 \mathrm{~h}$ at 20 to $25^{\circ} \mathrm{C}$. Diameters are read and a regression line is generated from the Midlands bovine serum calibrator. A plate is considered acceptable if the coefficient of determination is greater than 0.97 for the standard curve and the mean values obtained for the reference colostrum are the expected values $\pm 10 \%$. If a plate does not meet these criteria, it is repeated. If a sample falls outside the standard curve, it is retested at a different dilution so that it falls inside the standard curve values.

\section{Statistical Analysis}

Optical and digital Brix refractometer scores were plotted against each other for both fresh and frozen colostrum samples. Descriptive statistics were used to compare the optical Brix refractometer scores for fresh and frozen colostrum samples and digital Brix refractometer scores for fresh and frozen samples as well to compare both Brix refractometers to the RID. A Spearman rank coefficient of correlation was calculated to determine the level of relationship between the instruments. Two-tailed $t$-tests were performed to determine statistical differences between the optical and digital Brix refractometer instruments. Epidemiological diagnostic test characteristics (sensitivity, specificity, and predictive values) were calculated to compare the optical and digital Brix refractometers to the RID gold standard. Predictive values were calculated using the prevalence of samples with an RID IgG concentration of greater than or less than $50 \mathrm{~g} / \mathrm{L}$ and a Brix reading below or above the cut points tested.

\section{RESULTS}

\section{Descriptive Analysis}

A total of 288 fresh colostrum samples were collected from Holstein dairy cows between March 2008 and Jan- uary 2009. Eighty-two samples were from first-lactation cows, 81 samples were from second-lactation cows, and 122 samples were from third-lactation and greater cows. Of these samples, 114, 22, and 152 were collected from University of Guelph Elora Dairy Research Centre, the commercial herd in eastern Ontario, and the University of Minnesota Transition Management Facility, respectively. In the end, 15 frozen samples were missing and thus not available for analysis. As such, 273 colostrum samples were assessed for Ig concentrations by the laboratory RID. The RID Ig concentrations displayed a normal distribution and ranged from 22.4 to $196.9 \mathrm{~g} / \mathrm{L}$ (Figure 1). The mean and median of the RID Ig concentrations were 94.4 and $91.8 \mathrm{~g} / \mathrm{L}$, respectively. Only $7.7 \%$ of samples were below the standard cut-off point of $50 \mathrm{~g} / \mathrm{L}$ for Ig concentration.

The Brix scores ranged from 13.5 to $32.0 \%$ and 13.6 to $37.0 \%$ for the optical and digital Brix refractometers, respectively. The distribution of the optical and digital Brix refractometer scores for fresh colostrum samples is shown in Figure 2. The fresh and frozen samples measured using the optical Brix had a mean and median Brix score of 26.1 and $26.0 \%$ and 26.1 and $26.2 \%$, respectively. For the optical Brix refractometer, 21 of the fresh samples and 22 of the frozen samples measured above $32.0 \%$, truncating the upper level of the distribution (Figure 2). The fresh and frozen samples measured using the digital Brix instrument had a mean and median Brix value of 26.3 and $26.4 \%$ and 26.3 and $26.5 \%$, respectively. For the digital Brix refractometer, scores for fresh and frozen colostrum samples were normally distributed. There was no evidence of a difference between fresh and frozen samples when using the optical or digital Brix refractometers $(\mathrm{r}=0.98, P<0.001$ and $\mathrm{r}=0.97, P<0.001$ for fresh and frozen samples, respectively).

\section{Correlation Coefficients}

Correlation between both refractometer instruments for fresh and frozen samples and the gold standard laboratory RID was determined using correlation plots of the 273 colostrum samples. For RID analysis, only frozen samples were used. The correlation between the RID values and the optical Brix values for measuring frozen samples was $0.71(P<0.001 ; \mathrm{n}=272$; Figure 3$)$. Similarly, the correlation between the RID and digital Brix values of frozen samples was $0.73(P<0.001 ; \mathrm{n}=$ 273; Figure 3). In addition, it was found that for both instruments measuring fresh and frozen samples, firstlactation heifers had higher correlation coefficients, ranging between 0.77 and $0.83(P<0.001 ; \mathrm{n}=273)$. Third-lactation or greater animals had the next highest correlation coefficients, ranging between 0.71 and 


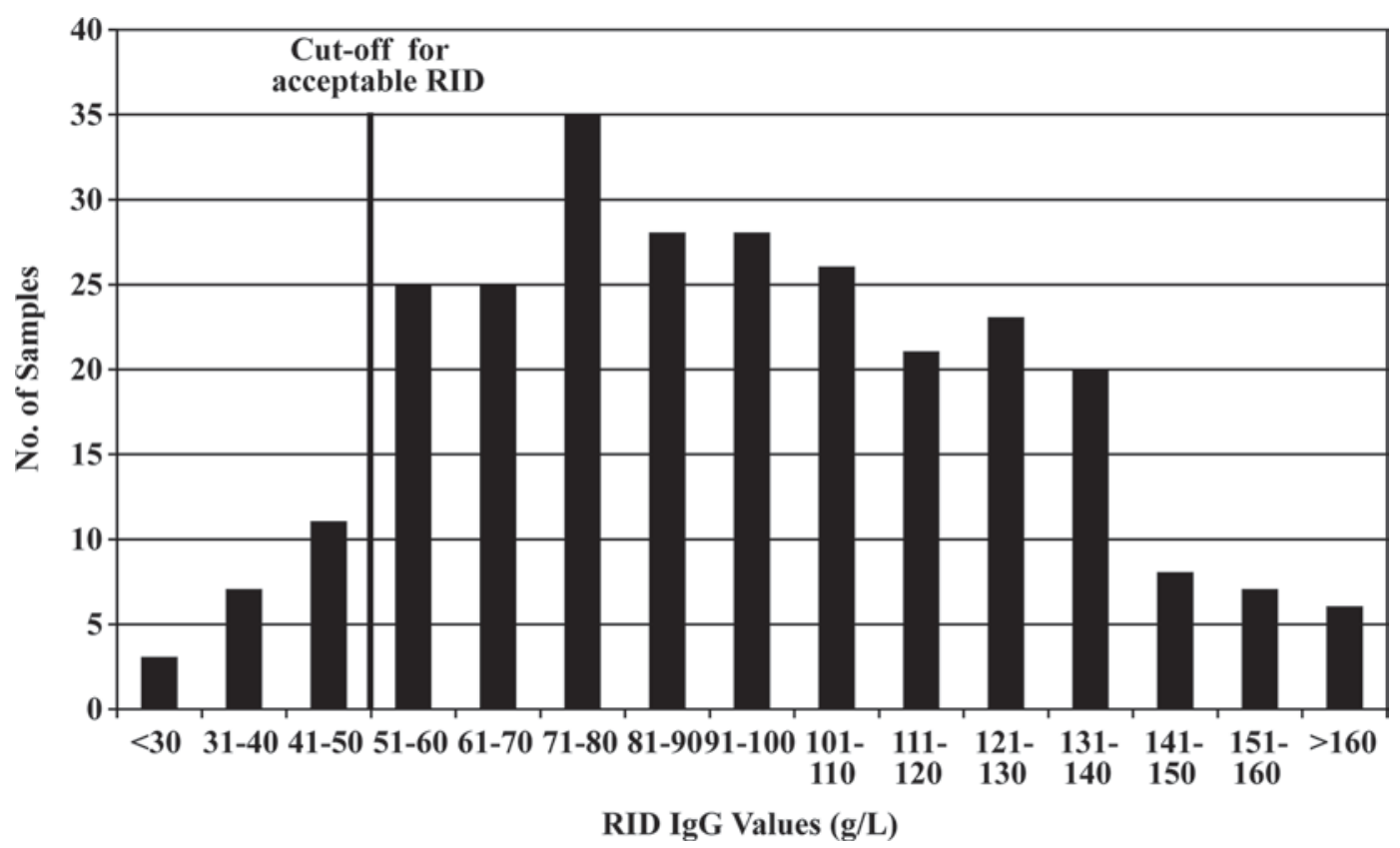

Figure 1. A distribution plot of the radial immunodiffusion assay (RID) IgG concentrations of 273 colostrum samples from 3 Holstein dairy herds.

0.73 , and the second-lactation animals had correlation coefficient values between 0.68 and $0.71(P<0.001$; n $=273 ;$ Figure 4 ).

Correlation between the optical and digital Brix refractometer instruments for fresh and frozen Brix scores was determined. It was found that Brix scores for fresh and frozen colostrum samples measured by the optical Brix were strongly correlated $(\mathrm{r}=0.98 ; P<0.001 ; \mathrm{n}=$ 288). Brix scores for fresh and frozen colostrum samples measured by the digital Brix were also highly correlated

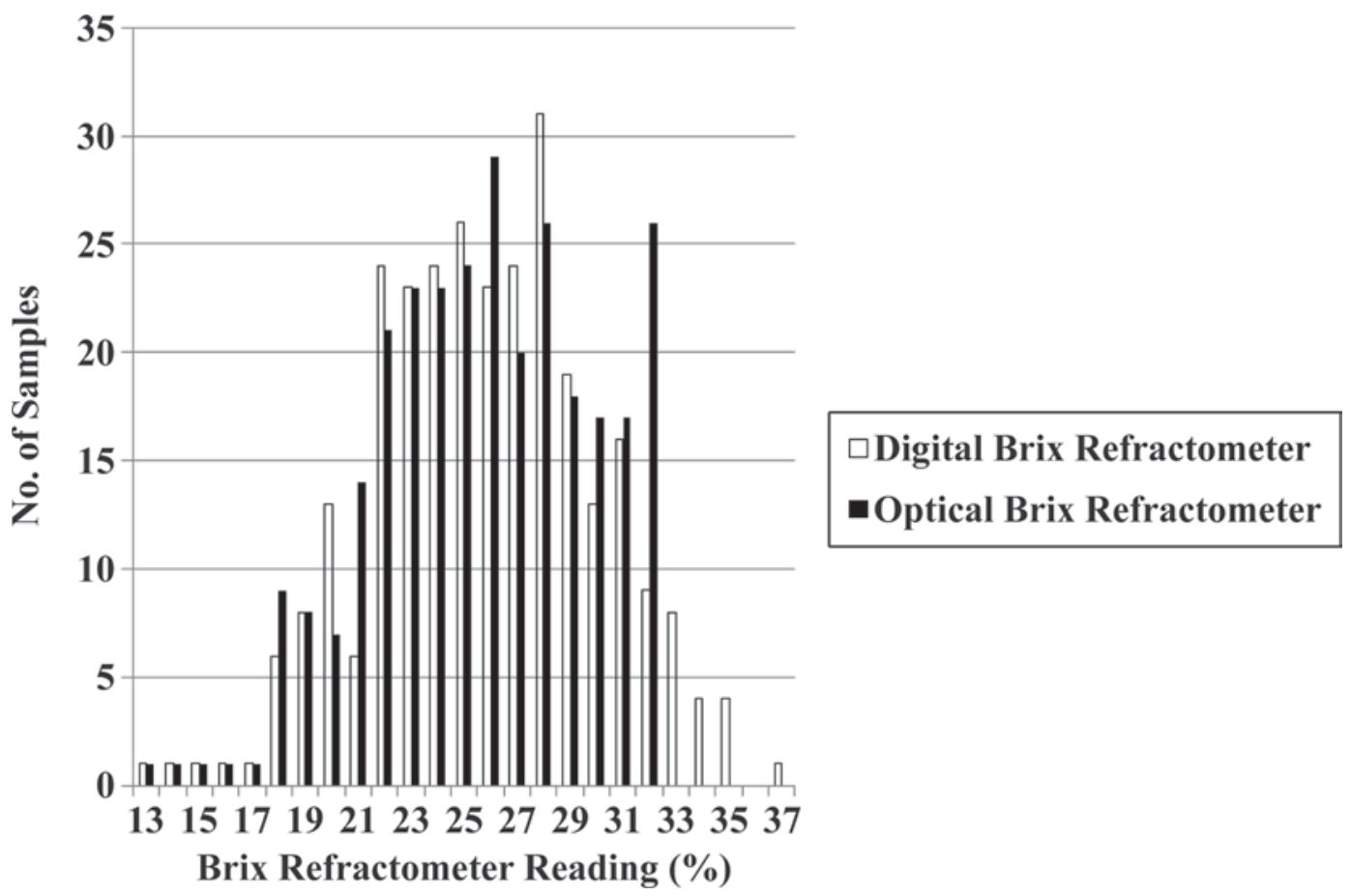

Figure 2. A distribution plot of optical and digital Brix refractometer readings (\%) for 287 fresh colostrum samples. The optical refractometer had an upper limit, on the scale, of $32 \%$, resulting in a truncated tail in the distribution. 


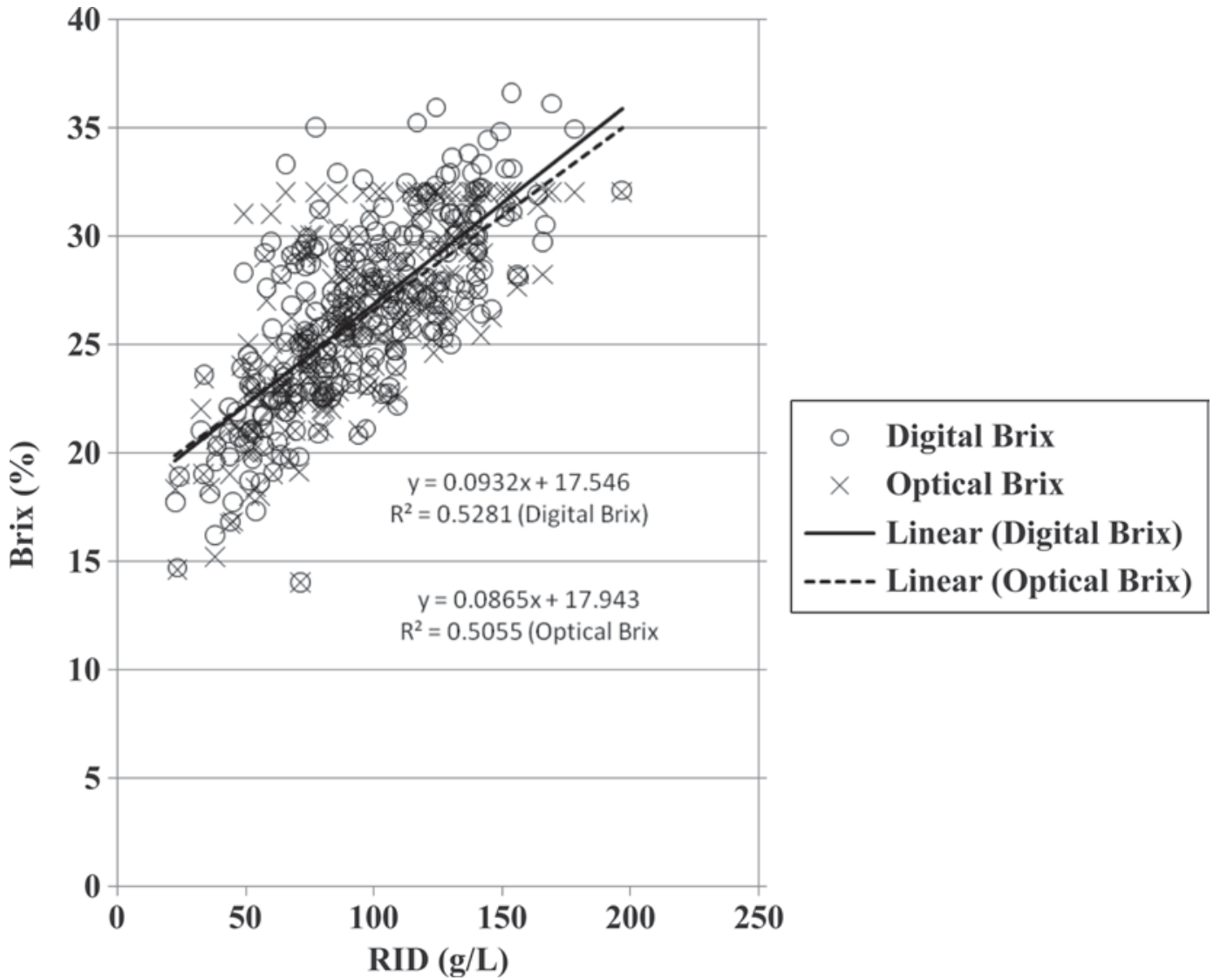

Figure 3. A correlation plot between the optical and digital Brix instrument readings of TS and the laboratory radial immunodiffusion assay (RID) readings of $\mathrm{IgG}$ for frozen colostrum samples $(\mathrm{n}=273)$.

$(\mathrm{r}=0.97 ; P<0.001 ; \mathrm{n}=288)$. When comparing Brix values for fresh and frozen colostrum samples between the optical and digital Brix refractometer instruments, both were found to have a strong correlation $(\mathrm{r}=0.98$, $P<0.001$ and $\mathrm{r}=0.97, P<0.001$, respectively; $\mathrm{n}=$ 288).

\section{Diagnostic Test Characteristics for All Colostrum Samples}

Optical and digital Brix refractometer instruments for both fresh and frozen samples were analyzed for test characteristics against the gold standard RID test. A positive sample was defined as containing an Ig concentration above the cut-off of $50 \mathrm{~g} / \mathrm{L}$ on the RID gold standard laboratory test. For assessment of the Brix instruments, 3 different cut-off levels were used for the Brix scores: 18,20 , and $22 \%$. The calculated sensitivity and specificity of the instruments were used to identify appropriate cut-off points to be used. For the optical Brix measuring fresh samples, the highest values for sensitivity and specificity were found to be at the $22 \%$ cut-off level at 90.5 and 85.0\%, respectively. Similarly, using a cut-off level of $22 \%$ for the digital Brix to measure fresh colostrum samples resulted in a sensitivity and specificity of 92.5 and $80.0 \%$, respectively.

\section{Diagnostic Test Characteristics for Colostrum Samples from Heifers and Cows}

Diagnostic test characteristics were also assessed for fresh colostrum samples taken from first-calf heifers and cows measured by both the optical and digital Brix refractometers against the gold standard RID laboratory test (Table 1). Test characteristics were considered for consecutive cut-off levels from 17 to $25 \%$ Brix scores for both optical and digital Brix refractometer instruments. Results were also evaluated from first-calf heifers and cows in second lactation or greater. Of the 273 colostrum quality results, 3 animals did not have a recorded lactation number; as such, these animals were removed from the analysis.

For the 79 samples taken from first-calf heifers measured by the optical Brix refractometer, the sensitivity and specificity at a $21 \%$ Brix cut-off level was 97.2 and $62.5 \%$, respectively, with a positive predictive value of 
Table 1. Diagnostic test characteristics for the optical and digital refractometers measuring fresh colostrum compared with the gold standard radial immunodiffusion assay assessment ${ }^{1}$

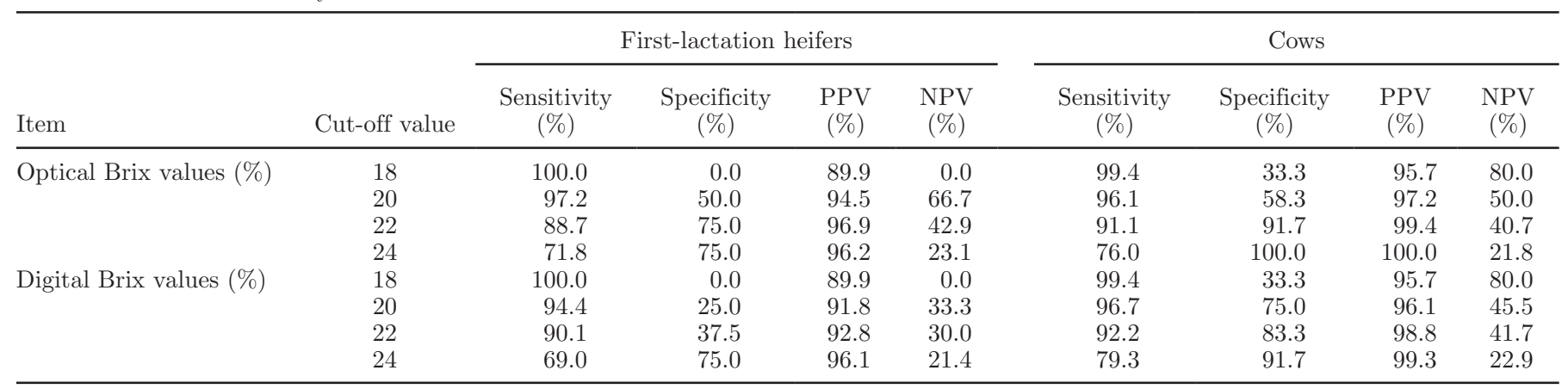

${ }^{1} \mathrm{PPV}=$ positive predicted value $\mathrm{NPV}=$ negative predicted value.

$95.8 \%$ and a negative predictive value of $71.4 \%$. At a cut-off level of $22 \%$ Brix, the test characteristics were very similar (Table 1). For these same 79 samples taken from first-calf heifers measured by the digital Brix refractometer, the highest combined values for sensitivity and specificity were seen at the $21 \%$ Brix cut-off level (97.2 and 75.0\%, respectively). For the 191 samples taken from cows in second lactation and greater, the diagnostic test characteristics were very similar to the first-calf heifers (Table 1).

\section{DISCUSSION}

It is worth mentioning that the average Brix values for optical and digital instruments determined in this study, for both first-calf heifers and older cows, are higher than those found in the recent Colorado report (Dinsmore and Skidmore, 2008). The average RID values for the colostrum samples as well as the percentage of samples above $50 \mathrm{~g} / \mathrm{L}$ are lower in the Colorado report.

The correlation plots for the optical and digital Brix instruments, for both fresh and frozen colostrum samples, against the RID determinations were not as high as the correlation coefficients between the 2 instruments. In addition, these values are not as high as the findings of a study to evaluate the use of Brix refractometry on equine colostrum (Chavatte et al., 1998). In mares, it was found that measurements made with the Brix refractometer were highly correlated

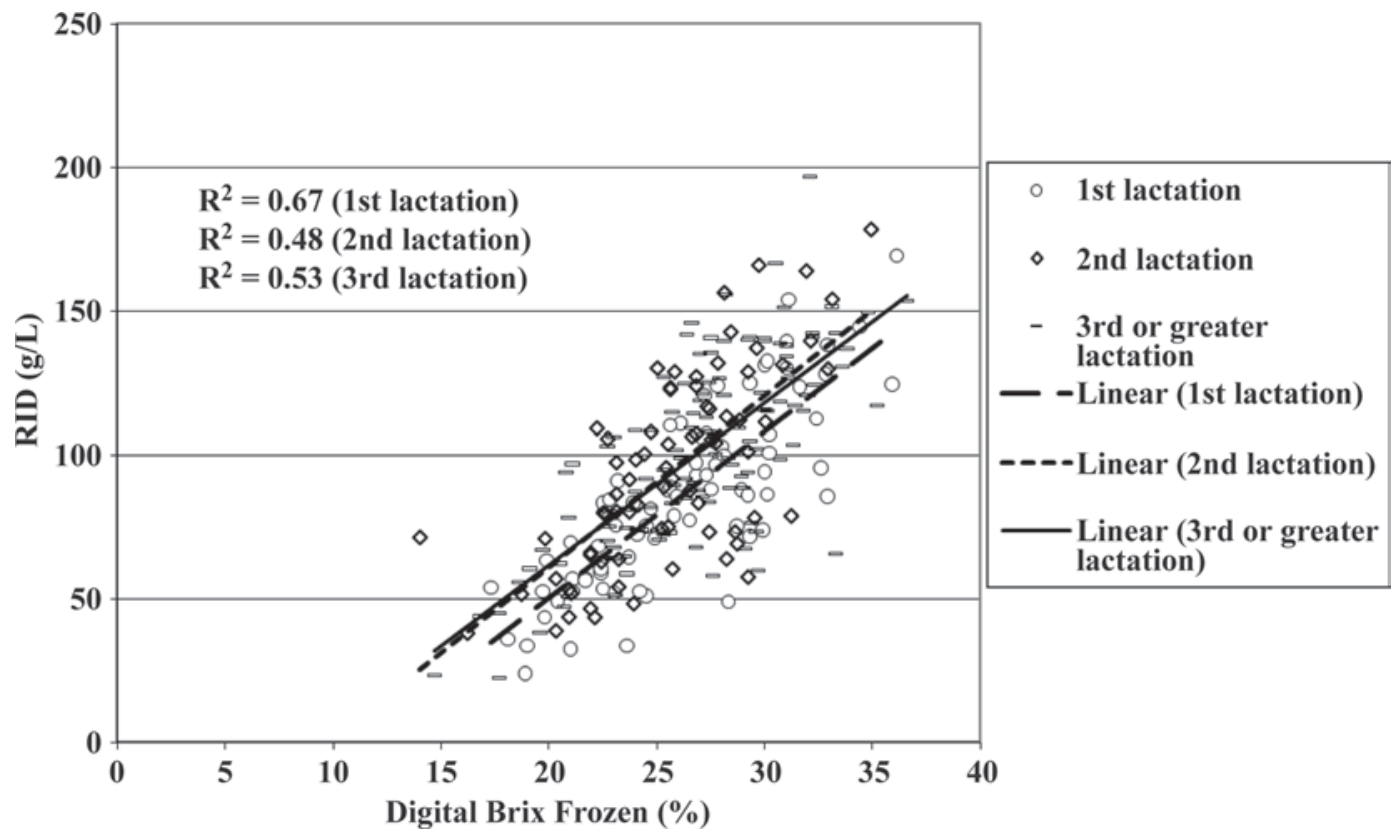

Figure 4. Scatter plot of the correlation between frozen colostrum samples analyzed by the digital Brix refractometer and the radial immunodiffusion assay (RID) and stratified by parity $(\mathrm{n}=273)$. 
with Ig concentrations determined by RID $\left(\mathrm{R}^{2}=0.85\right)$. However, the coefficient of determination values found in the current study are similar to those of a previously reported study in cows $\left(\mathrm{R}^{2}=0.56\right.$; Dinsmore and Skidmore, 2008). This may be attributable in part to the composition and the volume that is produced by horses and cows. Lavoie et al. (1989) reported that an average volume of $5.1 \mathrm{~L}$ (ranging from 3.2 to $7.0 \mathrm{~L}$ ) of colostrum was produced by mares and the colostral IgG contents averaged $440 \mathrm{~g}$. In another study, the TS and fat content of equine colostrum were reported to be 24.25 and 26.28\% (Csápo et al., 1995). In comparison, average colostral volume in cows was $11.2 \mathrm{~L}$ (ranging from 2.8 to $21.5 \mathrm{~L}$ ) and contained 93 to $259 \mathrm{~g} / \mathrm{L}$ of colostral protein and 23 to $125 \mathrm{~g} / \mathrm{L}$ of fat (Morin et al., 2001). Mean percentage for fat, TS, and TP in bovine colostrum were reported to be $6.7,27.64$, and $14.9 \%$, respectively. Thus, perhaps volume and the proportion of colostral protein in the colostrum would have an effect on the accuracy of the refractometer. In addition, fat globules and casein micelles in milk may alter the refractive index of milk (Fox and McSweeney, 1998). Dinsmore and Skidmore (2008) reported that the fat level of a sample may result in a wide band of color transition when reading the Brix refractometer. Subsequently, the recorded value may have been affected by fat content of the colostrum. Therefore, it is plausible that differences in the composition of colostrum from different species, especially high levels of fat and TS, could influence results.

As seen in the current results, there is a high correlation between the optical and digital Brix readings for both fresh and frozen colostrum samples. This finding suggests that both instruments are very useful for measuring Ig concentrations in colostrum samples and that freezing and thawing samples does not alter the readings of the 2 instruments. The correlation between fresh and frozen samples for the digital Brix is slightly lower than results for the optical Brix refractometer. This finding may have resulted from 4 outlying points that differ greatly in the 2 measurements. It is possible that these outlier points may be the result of recording errors or instrument malfunction.

The fact that the optical and digital Brix refractometers readings are highly correlated suggests that there was little difficulty in the current study in reading the scale on the optical Brix instrument and assigning an appropriate measurement. Future studies involving the use of the optical Brix refractometer should note the occurrence of a wide band formation instead of a definite line across the scale. However, perhaps readings that are above the $25 \%$ level are of little practical relevance because these levels are well above the suggested cut-off of $22 \%$. As such, these readings are not important in deciding between good quality and poor quality colostrum.

\section{Diagnostic Test Characteristics}

To ensure that high quality colostrum is fed to calves, appropriate Brix score cut-off levels need to be determined that strongly correspond to RID values over 50 $\mathrm{g} / \mathrm{L}$. For this study, the diagnostic test characteristics were established for both Brix instruments and for colostrum samples from first-calf heifers and older cows. These calculations provided an opportunity to identify differences in detection of quality colostrum samples for first-calf heifers and older cows that may indicate the need to have different cut-off levels for animals of different parities.

For first-calf heifers, the optimal cut-off level for the digital Brix refractometer was 21\%. Using this cut-point, the sensitivity and specificity were high, indicating that the instrument can successfully identify colostrum samples with adequate Ig concentrations. For the optical Brix refractometer instrument, there were similar sensitivity and specificity results for the 21 and $22 \%$ cut-off levels. Because it has been shown that colostrum of heifers is often inferior to that of older cows (Oyeniyi and Hunter, 1978), it would seem logical to have a lower cut-off level for first-calf heifers. Nevertheless, in the current study, the sensitivity and specificity at the $21 \%$ cut-off level in samples from heifers were high, indicating the optical Brix instrument can identify between high and low quality colostrum samples with few false negatives. For cows in second lactation and greater, the optimal cut-off level was $22 \%$ for both the optical and the digital Brix instruments.

The diagnostic test characteristics determined in this study were very similar to those in the report of Dinsmore and Skidmore (2008), with the exception that these authors found that an appropriate cut-off level for first-lactation heifers was $23 \%$, yielding a sensitivity of $84.6 \%$ and a specificity of $56.3 \%$. It is suggested that an appropriate Brix score cut-off level of $22 \%$ could be used for both cows and first-lactation heifers for selection of good quality colostrum. Similarly, a study by Chigerwe et al. (2008) in which researchers compared 2 hydrometers and an electronic refractometer for estimating colostral Ig concentrations determined that the optimal cut point for a digital refractometer was $22 \%$.

\section{Association of RID Values with Parity}

It is a common belief that colostrum from first-calf heifers is inferior in its Ig content compared with that of later-lactation cattle. Oyeniyi and Hunter (1978) reported a gradual increase in colostral Ig concentration 
in Holsteins with increasing parity. From the current study, it was apparent that Ig concentration increases with parity. First-lactation heifers had the greatest distribution colostrum samples under the $50 \mathrm{~g} / \mathrm{L}$ RID cut-off level. Second-lactation and then third-lactation or greater animals followed in their distributions of low RID colostrum samples. Yet, the average Brix scores for both the optical and digital instruments were similar, or slightly higher, for first-calf heifers compared with older animals. This finding supports a study by Pritchett et al. (1991) in which the Ig concentration of colostrum samples from 919 Holstein cows was examined. These authors determined that cows in their first lactation produced colostrum with a mean IgG1 concentration equal to that of second lactation. Thirdlactation or greater cows had samples with the highest IgG1 concentration. These findings were also confirmed by Tyler et al. (1999), who examined colostral Ig levels of Holstein and Guernsey cows. Finally, a recent study from Norway found that IgG concentration was significantly higher in fourth-lactation cows compared with first- or second-lactation cows. Actually, the lowest IgG values were found for second-lactation cows (Gulliksen et al., 2008). From the current study, as well from the other studies cited, it is clear that parity of the dam influences the $\operatorname{IgG}$ concentration of colostrum.

At present, the colostrometer is the tool most commonly used to assess colostrum quality before feeding calves (National Animal Health Monitoring System, 2010). However, as described by Mechor et al. (1992), the temperature-sensitive nature of the colostrometer as well as its fragile design make it less than desirable as an on-farm tool. In addition, the test characteristics for the colostrometer leave room for misclassification of samples. The Brix refractometers perform well at any temperature (Bielmann et al., 2008) and have high correlation compared with the RID. These instruments are durable and affordable and the calibration process is a simple. Incorporating the use of a refractometer into the colostrum management protocol on farm would be beneficial, allowing producers to be confident that quality colostrum is fed to calves and influence passive transfer of immunity. These instruments offer a novel and accurate method of assessing colostrum quality before feeding calves.

\section{CONCLUSIONS}

Brix refractometers, both digital and optical, have acceptable test sensitivities and specificities when compared with the gold standard RID laboratory test, indicating that they are capable of differentiating between good and poor quality colostrum. From this study, it is suggested that the appropriate cut-off level is a Brix score equal to or above $22 \%$ to ensure colostrum is of good quality and is not dependent on whether the sample is fresh or thawed from a frozen state. Both the optical and digital Brix refractometers show considerable potential for being useful management tools to be included in a colostrum monitoring program to improve neonatal calf health on dairy operations.

\section{REFERENCES}

Beam, A. L., J. E. Lombard, C. A. Kopral, L. P. Garber, A. L. Winter, J. A. Hicks, and J. L. Schlater. 2009. Prevalence of failure of passive transfer of immunity in newborn heifer calves and associated management practices on US dairy operations. J. Dairy Sci. 92:3973-3980.

Bielmann, V., J. Garner, C. Throop, N. Perkins, and K. Leslie. 2008. An evaluation of a Brix refractometer for measurement of colostrum quality and success of passive transfer. J. Dairy Sci. 91(E-Suppl. 1):354.

Boyd, J. W. 1972. The relationship between serum immune globulin deficiency and disease in calves: A farm survey. Vet. Rec. 90:645649 .

Chavatte, P., F. Clement, R. Cash, and J. F. Grongnet. 1998. Field determination of colostrum quality by using a novel, practical method. Pages 206-209 in AAEP Proceedings. Vol. 44.

Chelack, B. J., P. S. Morley, and D. M. Haines. 1993. Evaluation of methods for dehydration of bovine colostrum for total replacement of normal colostrum in calves. Can. Vet. J. 34:407-412.

Chigerwe, M., J. W. Tyler, J. R. Middleton, J. N. Spain, J. S. Dill, and B. J. Steevens. 2008. Comparison of four methods to assess colostral IgG concentration in dairy cows. J. Am. Vet. Med. Assoc. 233: 761-766.

Csápo, J., J. Stefler, T. G. Martin, S. Makray, and Zs. Csapó-Kiss. 1995. Composition of mares' colostrum and milk. Fat content, fatty acid composition and vitamin content. Int. Dairy J. 5:393-402.

Dinsmore, P., and A. Skidmore. 2008. Comparison of Brix (sugar) refractometer and colostrometer for evaluation of colostrum quality in dairy cows. J. Dairy Sci. 91(E-Suppl. 1):355. (Abstr.)

Donovan, G. A., L. Badinga, R. J. Collier, C. J. Wilcox, and R. K. Braun. 1986. Factors influencing passive transfer in dairy calves. J. Dairy Sci. 69:754-759.

Fleenor, W. A., and G. H. Stott. 1980. Hydrometer test for estimation of immunoglobulin concentration in bovine colostrum. J. Dairy Sci. 63:973-977.

Fox, P. F., and P. L. H. McSweeney. 1998. Dairy Chemistry and Biochemistry. Chapman and Hall, London, UK.

Gulliksen, S. M., K. I. Lie, L. Solverold, and O. Ostera. 2008. Risk factors associated with colostrum quality in Norwegian dairy cows. J. Dairy Sci. 91:704-712.

Lavoie, J. P., M. S. Spensely, B. P. Smith, and J. Mihalyi. 1989. Colostral volume and immunoglobulin $\mathrm{G}$ and $\mathrm{M}$ determinations in mares. Am. J. Vet. Res. 50:466-470.

McEwan, A. D., E. W. Fisher, and I. E. Selman. 1970. Observations on the immune globulin levels of neonatal canes and their relationship to disease. J. Comp. Pathol. 80:259-265.

McGuire, T. C., N. E. Pfeiffer, J. M. Weikel, and R. C. Bartsch. 1976. Failure of colostral immunoglobulin transfer in calves dying from infectious disease. J. Am. Vet. Med. Assoc. 1697:713-718.

Mechor, G. D., Y. T. Gröhn, L. R. McDowell, and R. J. Van Saun. 1992. Specific gravity of bovine colostrum immunoglobulins as affected by temperature and colostrum components. J. Dairy Sci. 75:3131-3135.

Moore, D. A., J. Taylor, M. L. Hartman, and W. M. Sischo. 2009 Quality assessments of waste milk at a calf ranch. J. Dairy Sci. 92:3503-3509.

Moore, M., M. Chigerwe, M. E. Dawes, J. W. Tyler, and J. R. Middleton. 2005. Effect of delayed colostrum collection on colostral IgG concentration in dairy cows. J. Am. Vet. Med. Assoc. 226:1375-1377. 
Morin, D. E., P. D. Constable, P. Maunsell, and G. C. McCoy. 2001. Factors associated with colostral specific gravity in dairy cows. J. Dairy Sci. 84:937-943.

National Animal Health Monitoring System. 2010. Heifer calf health and management practices on US dairy operations, 2007. Animal and Plant Health Inspection Service, Veterinary Services, USDA, Fort Collins, CO.

Naylor, J. M., and D. S. Kronfeld. 1977. Refractometry as a measure of the immunoglobulin status of the newborn dairy calf: Comparison with zinc sulfate Turbidity test and single radial immunodiffusion. Am. J. Vet. Res. 38:1331-1334.

Oyeniyi, O. O., and A. G. Hunter. 1978. Colostral constituents including immunoglobulins in the first three milkings postpartum. J. Dairy Sci. 61:44-48.

Pritchett, L. C., C. C. Gay, T. E. Besser, and D. D. Hancock. 1991. Management and production factors influencing immunoglobulin G1 concentration in Holstein colostrum. J. Dairy Sci. 74:23362341.
Pritchett, L.C., C.C. Gay, D.D. Hancock, and T.E. Besser. 1994. Evaluation of the hydrometer for testing immunoglobulin G1 concentrations in Holstein colostrum. J. Dairy Sci. 77:17611767.

Trotz-Williams, L. A., K. E. Leslie, and A. S. Peregrine. 2008. Passive immunity in Ontario dairy calves and investigation of its association with calf management practices . J. Dairy Sci. 91:3840-3849.

Tyler, J. W., D. D. Hancock, and S. E. Wicksie. 1998. Use of serum total protein concentration to predict mortality in mixed-source dairy replacement heifers. J. Vet. Intern. Med. 12:79-83.

Tyler, J. W., B. J. Steevens, and D. E. Hostetler. 1999. Colostral IgG concentrations in Holstein and Guernsey cows. Am. J. Vet. Res. 60:1136-1139.

Weaver, D. M., J. W. Tyler, D. C. VanMetre, D. E. Hostetler, and G. M. Barrington. 2000. Passive transfer of colostral immunoglobulins in calves. J. Vet. Intern. Med. 14:569-577. 